\title{
Grey Prediction Model-Based Chinese Sports Venues Construction Deve- lopment Trend Prediction Research
}

\author{
Jianbao Jiang and Guohua Zheng* \\ College of Physical Education, Ningbo University, Ningbo 315211, Zhejiang, China
}

\begin{abstract}
The living standards of people is increasing day by day, they also have pursued more on health. Physical exercise is a kind of way that people pursue physical health. With more and more people participate in physical exercises, Chinese sports venues amount has become a topic of people's concerns. The paper based on all previous sports venues statistical quantity, from indoors venues, outdoors venues, growth rate, accumulative quantity multiple perspectives, utilizes grey model to predict future Chinese each kind of venues status. By comprehensive analyzing, it gets following conclusions that indoors sports venues' completion speed is larger than outdoors sports venues' completion speed. Sports venues' each kind of field growth rate until year 2044-2049 will get close to 0\% and arrive at saturation. Indoors sports venues may replace outdoors sports venues.
\end{abstract}

Keywords: Grey Theory, Prediction Model, Sports Venues, Physical Health, Physiological Indicator.

\section{INTRODUCTION}

Since Beijing Olympic Games succeeded in hosting in 2008, national people's physical exercises consciousness has greatly improved. No matter children or old people, all of them have passions for sports [1]. Followed by the phenomenon, it occurs problem is sports venues development status. At present, more sports venues in nationwide have fallen into disuse. Such as, Liaoning sports venue blast in 2007, Beijing Wukesong baseball stadium was dismantled [2]. Chinese established sports venues before years, whether intact maintain or not, whether can continue to normal use, Chinese sports venues quantity can meet national fitness demand or not. These problems become focus of numerous relative experts, scholars [3].

In 2006, Hu Qin-Shan and others in the article "Discuss on Chinese comprehensive large-scale sports venues development systematic obstacle problem" [4], they made comprehensive analysis of Chinese large-scale comprehensive sports venues constraining factors, pointed out seven kinds of important constraining factors, and made reasonable suggestions for existing seven kinds of problems [5]. In 2011, Xu Yan-Mei in the article "Sports venues development status and prospect exploration under market economy", she comprehensively analyzed sports venues from construction input to later period maintenance such whole process existing problems since opening-up and reform, and put forward proper renovation ways.

In 2012, Chen Xiang and others in the article " Public sports venues development ways transformation in the per- spective of people's livelihood and finance", comprehensive discussed Chinese sports venues transformational development ways in the view of people's livelihood, and put forward seven kinds of means to propel to venues transformational development. In 2013, Chen Feng-Jun in the article "Chinese sports venues development status and countermeasures research in the background of building sports power" made comprehensive discussion on sports power such a key vocabulary and comprehensive analyzed current Chinese sports venues development problems [6, 7].

In recent years, China has gradually stood among world powers. Chinese sports are rising steadily. In order to promote national physical quality, Chinese government constantly increases investment in building sports venues. And meanwhile, followed by people consumption increment in sports, sports have gradually also become one part of the tertiary industry [8]. Lots of investors are giving more confidence to Chinese sports market, and successively invest and build venues in China [9]. How is Chinese sports venues quantity growth rate, how many sports venues in future China, these problems lead people thinking. The paper will base on previous national sports venues census data, studies Chinese future sports venues quantities and sports venues quantities development trend.

\section{MODEL ESTABLISHMENT}

As Table 1, data is from yearbook of general administration of sports of China.

\subsection{Grey System $G M(1,1)$ Model}

Grey system $G M(1,1)$ model is according to known lots of data, ranking these data according to time, fitting according to differential equations to draw near time sequence described dynamic process, by parity of reasoning, 
arriving at prediction target value. Such fitting method obtained model is time sequence one order differential equation.

Grey model contains two concepts that are respectively, $A G O$ and $I A G O$.

(1) 1-AGO Represents accumulated generating operation number, it refers to one time accumulated generating operation. Record original sequence as:

$$
F_{i j}=S_{i j} \times P
$$

One time accumulated generating operation sequence is:

$$
X^{(1)}=\left\{X^{(1)}(1), X^{(1)}(2), \cdots, X^{(1)}(n)\right\}
$$

Among them,

$$
x^{(1)}(k)=\sum_{i=0}^{k} x^{(0)}(i)=x^{(1)}(k-1)+x^{(0)}(k)
$$

(2) IAGO Represents inverse accumulated generating operation number, it is inverse operation of accumulated generating operation. Record original sequence as:

$$
X^{(1)}=\left\{X^{(1)}(1), X^{(1)}(2), \cdots, X^{(1)}(n)\right\}
$$

One time inverse accumulated generating operation sequence is:

$$
X^{(0)}=\left\{X^{(0)}(1), X^{(0)}(2), \cdots, X^{(0)}(n)\right\}
$$

Among them, $x^{(1)}(0)=0$

$$
x^{(0)}(k)=x^{(1)}(k)-x^{(1)}(k-1)
$$

$G M(1,1)$ Model represents one order, one variable grey system model. Use $X^{(0)}$ to repress sequence that needs modeling $X^{(1)}$ is $X^{(0)} 1-A G O$ sequence, and then it has:

$$
x^{(1)}(k)=\sum_{i=0}^{k} x^{(0)}(i)
$$

Regard $Z^{(1)}$ as $X^{(1)}$ adjoining neighborhood mean value $(M E A N)$ generating sequence:

$$
z^{(1)}(k)=\frac{x^{(1)}(k)+x^{(1)}(k-1)}{2}
$$

Then it can establish grey differential equation:

$$
x^{(0)}(k)+a z^{(1)}(k)=b
$$

Record $\hat{a}=(a, b)^{T}$, then grey differential equations least square estimated parameter sequence meets following formula:

$$
\hat{a}=\left(B^{T} B\right)^{-1} B^{T} Y_{n}
$$

Among them,

$$
\begin{gathered}
B=\left[\begin{array}{cc}
-\mathrm{z}^{(1)}(2) & 1 \\
-\mathrm{z}^{(1)}(3) & 1 \\
\vdots & \vdots \\
-\mathrm{z}^{(1)}(n) & 1
\end{array}\right] \\
Y_{n}=\left[\begin{array}{c}
x^{(1)}(2) \\
x^{(1)}(3) \\
\vdots \\
x^{(1)}(n)
\end{array}\right]
\end{gathered}
$$

Call $\frac{d x^{(1)}}{d t}+a x^{(1)}=b \quad$ as grey differential equation $x^{(0)}(k)+a z^{(1)}(k)=b$ whitening equation, is also called silhouette equation.

Based on above analysis, it has following relationships:

(1) Solution of whitening equation $\frac{d x^{(1)}}{d t}+a x^{(1)}=b$ is also called time response equation:

$$
\hat{x}^{(1)}(t)=\left(x^{(1)}(0)-\frac{b}{a}\right) e^{-a t}+\frac{b}{a}
$$

(2) $G M(1,1) \quad$ grey differential equation $x^{(0)}(k)+a z^{(1)}(k)=b$ time response sequence is:

$$
x^{(1)}(k+1)=\left[x^{(1)}(0)-\frac{b}{a}\right] e^{-a k}+\frac{b}{a}, k=1,2, \cdots, n
$$

(3)Select $x^{(1)}(0)=x^{(0)}(1)$, then:

$$
\hat{x}^{(1)}(k+1)=\left[x^{(0)}(1)-\frac{b}{a}\right] e^{-a k}+\frac{b}{a}, k=1,2, \cdots, n
$$

(4) Restore the value and can get:

$$
\hat{x}^{(0)}(k+1)=\hat{x}^{(1)}(k+1)-\hat{x}^{(1)}(k)
$$

Formula (16) is prediction equation.

\subsection{Analyze Matlab Computational Result}

Matlab prediction result is as following:

(1) Each kind of venues completion numbers prediction result:

Percent absolute error is: $6.0757 \%$

Predicted value is: 388485.28945 , 521933.53365, 701222.46825, 942098.78897, 1265718.3253 1700504.1274, 2284642.8225, 3069438.4931

For" predicted value", adopt " rounding off" method to extract as integer, corresponding to time frame, list out as Table 2, development curve is as Fig. (1). 


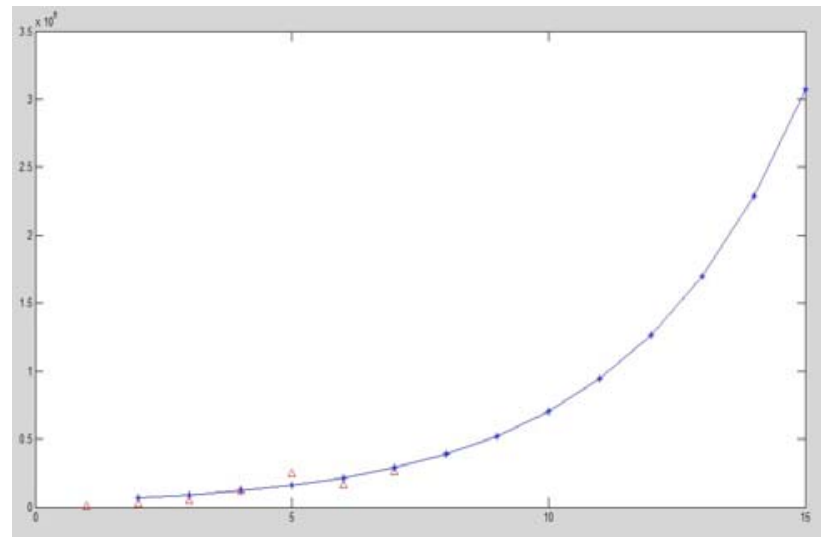

Fig. (1). The trends of the number of various venues built.

(2) Each kind of venues accumulated completion numbers prediction:

Percent absolute error is: $5.8726 \%$

Predicted value is: 1814439.2092, 2906831.87335, 4656905.28351, 7460619.59014, $\quad 11952324.8338$ $19148284.8317,30676610.3745,49145624.9131$

For "predicted value", adopt "rounding off" method to extract as integer, corresponding to time frame, list out as Table 2.

Fig. (2) is each kind of venues accumulated completion numbers corresponding time frame development trend chart.

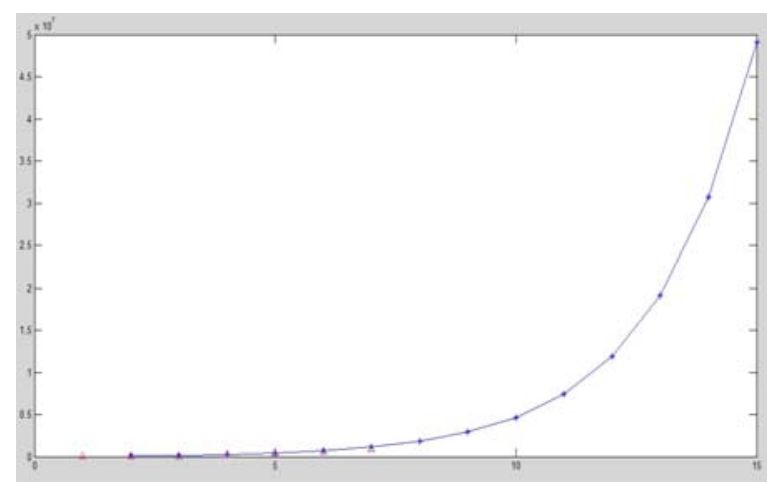

Fig. (2). The trends of the number of various cumulative venues.

(3) Each kind of venues growth rate prediction

Percent absolute error is: $3.0473 \%$

Predicted value is: 41.5348 30.9877, 23.1188, 17.2482, $12.8683,9.60056,7.16265,5.3438$

For "predicted value", adopt "rounding off" method to extract as two decimals, corresponding to time frame, list Table 3.

Fig. (3) is each kind of venues' growth rate corresponding time frame development trend chart. From Figure 3, it is clear that until year 2044-2049, each kind of venues growth rate gets closer to $0 \%$.

(4) Outdoors venues completion numbers prediction:

Percent absolute error is: $4.7876 \%$

Predicted value is: $326590.3216 \quad 424028.42111$

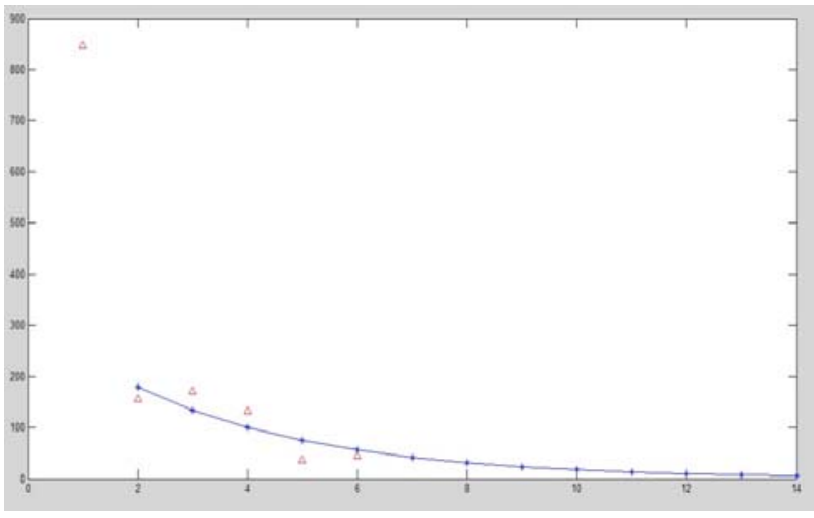

Fig. (3). The trends of growth rate of the number of various venues.

$\begin{array}{llll}50537.14092 & 714789.68966 & 928046.92449 & 1204929.375\end{array}$ 1564419.60052031163 .5994

For "predicted value", adopt "rounding off" method to extract as integer, corresponding to time frame, list out as Table 4.

Fig. (4) is outdoors venues' completion numbers corresponding time frame development trend chart.

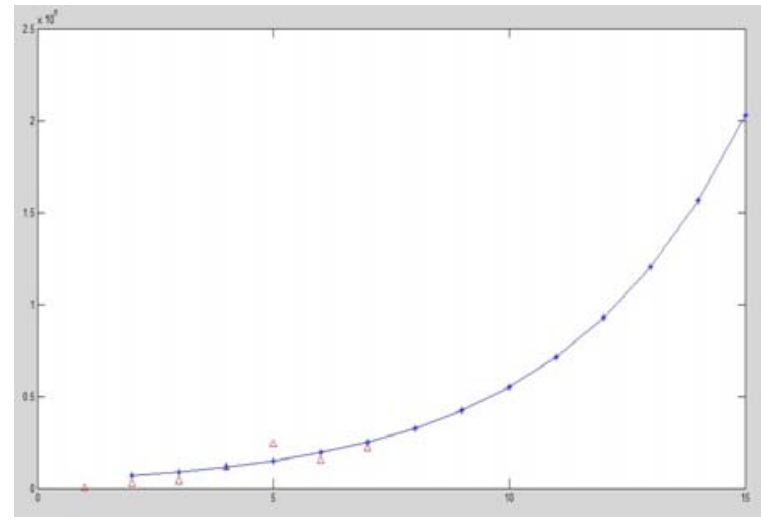

Fig. (4). The trends of the number of various outdoor venues.

(4) Outdoors venues accumulated completion numbers prediction:

Percent absolute error is: $9.3801 \%$

Predicted value is: $1673485.8974 \quad 2639627.83702$ $4163545.76324 \quad 6567256.59559 \quad 10358685.0355$ 16338992.409225771868 .922940650562 .2345

For "predicted value", adopt "rounding off" method to extract as integer, corresponding to time frame, list out as Table 5 .

Fig. (5) is outdoors venues accumulated completion numbers corresponding time frame development trend chart.

(5) Outdoors venues growth speed prediction:

Percent absolute error is: $3.3225 \%$

Predicted value is: $39.095728 .776521 .181 \quad 15.5903$ 11.47538 .446446 .217024 .57606

For"predicted value", adopt "rounding off" method to extract as two decimals, corresponding to time frame, list Table 6. 


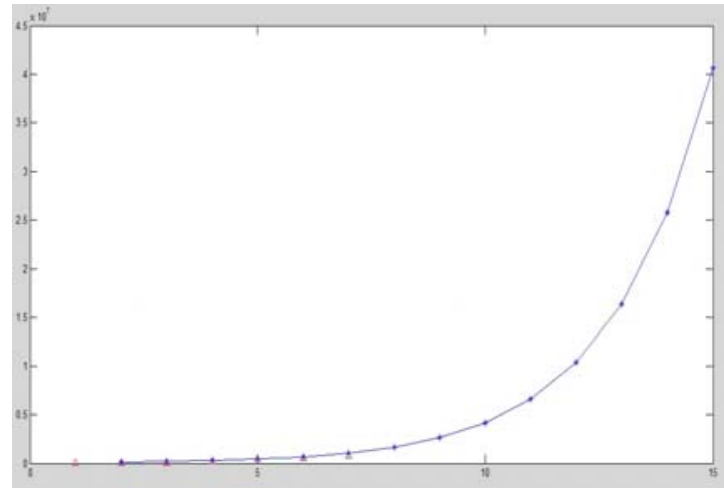

Fig. (5). The trends of the number of various cumulative outdoor venues.

Fig. (6) is outdoors venues' growth rate corresponding time frame development trend chart. From Figure, it is clear that until year 2044-2049, each kind of venues growth rate gets closer to $0 \%$.

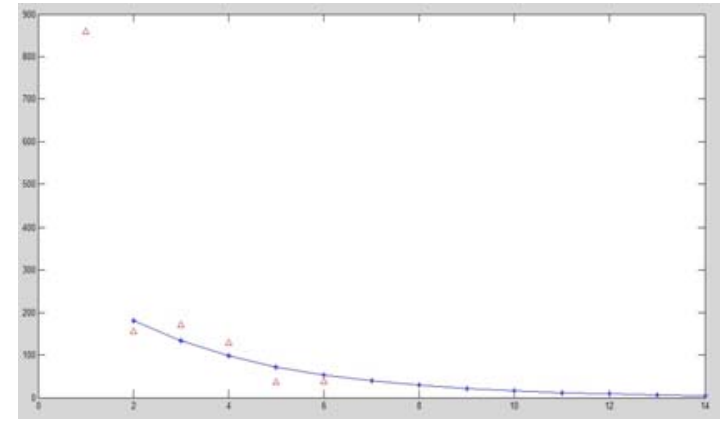

Fig. (6). The trends of growth rate of the number of various outdoor venues.

(7) Indoors venues development prediction Table 7.

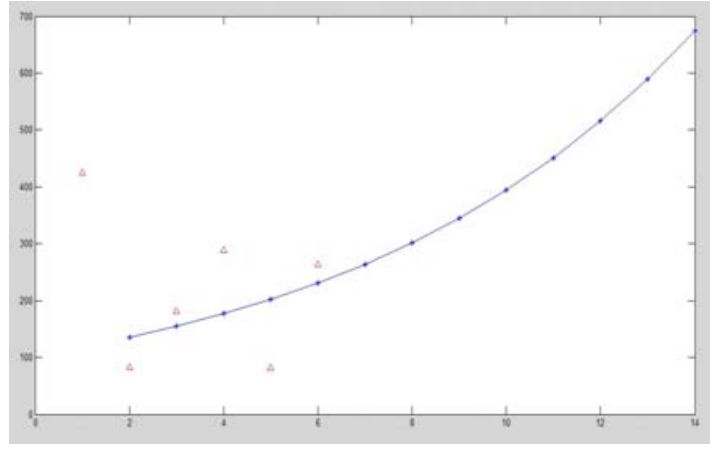

Fig. (7). The trends of growth rate of the number of various indoor venues.

(1) Indoors venues completion numbers prediction:

Percent absolute error is: $4.0817 \%$

Predicted value is: $149979.8552026 \quad 212785.8128067$

$\begin{array}{lll}584241.665112 & 722938.759962 & 1148752.18529\end{array}$
$3598897.26671 \quad 80908313.8755 \quad 103067596.2411$

(2) Indoors accumulation completion numbers prediction:

Percent absolute error is: $5.7131 \%$

Predicted value is: $297751.6905392 \quad 810210.8259958$ $2204661.143559 \quad 5999093.818509 \quad 16324108.0147$ $44419459.09454 \quad 120869596.3341 \quad 328897731.2146$

(3) Indoors venues growth rate prediction:

Percent absolute error is: $6.3199 \%$

Predicted value is: $264.2006 \quad 302.0364$ 674.2361

Fig. (7) is indoors venues development growth rate.

Table 1. Nationwide sports venues' development status.

\begin{tabular}{|c|c|c|c|c|c|c|c|c|c|}
\hline \multirow[b]{2}{*}{ Time } & \multicolumn{3}{|c|}{ Each kind of field } & \multicolumn{3}{|c|}{ Outdoors venues } & \multicolumn{3}{|c|}{ Indoors venues } \\
\hline & Completion(piece) & $\begin{array}{c}\text { Accumulation } \\
\text { (piece) }\end{array}$ & $\begin{array}{l}\text { Growth } \\
\text { rate\% }\end{array}$ & Completion(piece) & $\begin{array}{c}\text { Accumulation } \\
\text { (piece) }\end{array}$ & $\begin{array}{c}\text { Growth } \\
\text { rate\% }\end{array}$ & $\begin{array}{l}\text { Comple- } \\
\text { tion(piece) }\end{array}$ & $\begin{array}{l}\text { Accumula- } \\
\text { tion (piece) }\end{array}$ & $\begin{array}{c}\text { Growth } \\
\text { rate\% }\end{array}$ \\
\hline Before liberation & 2835 & 2835 & -- & 2776 & 2776 & -- & 79 & 79 & -- \\
\hline $\begin{array}{c}1949- \\
1960\end{array}$ & 24185 & 27040 & 847.10 & 23842 & 26618 & 858.90 & 343 & 422 & 424.20 \\
\hline $\begin{array}{c}1961- \\
1970\end{array}$ & 41855 & 68895 & 154.80 & 41503 & 68121 & 155.90 & 352 & 774 & 83.40 \\
\hline $\begin{array}{c}1971- \\
1980\end{array}$ & 11894 & 186989 & 171.40 & 116695 & 184816 & 171.30 & 1399 & 2173 & 180.70 \\
\hline $\begin{array}{c}1981- \\
1990\end{array}$ & 245492 & 432492 & 131.30 & 235224 & 42440 & 129.40 & 6268 & 8411 & 288.40 \\
\hline $\begin{array}{c}1991- \\
1995\end{array}$ & 158119 & 590600 & 36.60 & 151259 & 575299 & 35.70 & 6860 & 15301 & 81.30 \\
\hline $\begin{array}{l}1995- \\
2003\end{array}$ & 259480 & 850080 & 43.90 & 219103 & 794402 & 38.10 & 40377 & 55678 & 263.80 \\
\hline
\end{tabular}


Table 2. Each stage venues' completion numbers predicted value.

\begin{tabular}{|c|c|c|c|c|c|c|}
\hline Time frame & 2004-2009 & $2010-2013$ & 2014-2019 & $2020-2023$ & 2024-2029 & $\ldots$ \\
\hline
\end{tabular}

Table 3. Each kind of venues accumulated completion numbers.

\begin{tabular}{|c|c|c|c|c|c|c|}
\hline Time frame & $2004-2009$ & $2010-2013$ & 2014-2019 & $2020-2023$ & $2024-2029$ & $\ldots$ \\
\hline
\end{tabular}

Table 4. Each kind of venues growth rate prediction table.

\begin{tabular}{|c|c|c|c|c|c|c|}
\hline Time frame & $2004-2009$ & $2010-2013$ & $2014-2019$ & $2020-2023$ & $2024-2029$ & $\ldots$ \\
\hline Each kind of venues growth rate & $41.53 \%$ & $30.99 \%$ & $23.12 \%$ & $17.25 \%$ & $12.87 \%$ & $\ldots$ \\
\hline
\end{tabular}

Table 5. Outdoors field completion numbers prediction table.

\begin{tabular}{|c|c|c|c|c|c|c|}
\hline Time frame & 2004-2009 & $2010-2013$ & $2014-2019$ & $2020-2023$ & $2024-2029$ & $\ldots$ \\
\hline
\end{tabular}

Table 6. Outdoors venues accumulation completion numbers.

\begin{tabular}{|c|c|c|c|c|c|c|}
\hline Time frame & 2004-2009 & $2010-2013$ & 2014-2019 & $2020-2023$ & 2024-2029 & $\ldots$ \\
\hline
\end{tabular}

Table 7. Outdoors venues growth rate.

\begin{tabular}{|c|c|c|c|c|c|c|}
\hline Time frame & $2004-2009$ & $2010-2013$ & $2014-2019$ & $2020-2023$ & $2024-2029$ & $\ldots$ \\
\hline Outdoors venues growth rate & $41.53 \%$ & $30.99 \%$ & $23.12 \%$ & $17.25 \%$ & $12.87 \%$ & $\ldots$ \\
\hline
\end{tabular}

Table 8. Indoors venues development prediction table.

\begin{tabular}{|c|c|c|c|c|c|c|}
\hline Indoors venues completion numbers & 149980 & 212786 & 584212 & 722939 & 1148752 & $\ldots$ \\
\hline Indoors venues growth rate & $264.20 \%$ & $302.04 \%$ & $345.29 \%$ & $394.74 \%$ & $451.27 \%$ & $\ldots$ \\
\hline
\end{tabular}

\section{CONCLUSION}

Grey prediction method overcomes single data variable unpredictable difficulties. Grey prediction is not only applicable to sports venues numbers prediction, and also applicable to other aspects prediction, it has a wide range of application, and strong operability. But grey prediction method has certain limitations, it is applicable to occasions that original numbers are positive numbers, conform to or basic conform to index rules changes and changing speed is not so fast. And accuracy is not very high that needs lots of data supports. On the premise that meets the conditions, grey prediction method then may get good results. Grey prediction method has theoretical evidences and practical values, the method feature values are to be further studied.

Based on above analysis, it is clear that indoors sports venues completion speed is bigger than outdoors sports venues completion speed. Until 2044-2049year, sports venues each venue growth speed gets close to $0 \%$ and arrives at saturation. Indoors sports venues will replace outdoors sports venues. Outdoors sports venues and indoors sports venues have their own advantages and disadvantages. In recent years, air pollution status gets worse. Especially for haze, it interferences with people's life, indoors sports venues can ensure people to enjoy pleasure from sports in bad weather 
conditions. But indoors sports venues maintenance cost is also relative higher.

\section{CONFLICT OF INTEREST}

The authors confirm that this article content has no conflict of interest.

\section{ACKNOWLEDGEMENTS}

This work is supported by the Chinese ministry of education humanities and social science research project. Project number: 14YJA890003.

\section{REFERENCES}

[1] C. Li-bin, and J. Jun-Gang, "The role of local government in MICE," J. Huazhong. Univ. Sci. Technol (Soc. Sci. Ed), vol. 21, no. 5, pp. 67-70, 2007.

[2] D. Jie, "Existing mainly problems, reasons and countermeasures about china host mega sport events," Sports Sci., vol. 33, no. 3, pp. 42-51, 2012
[3] G. Hong-bo, and Z. Yong, "Analysis and strategic research on chinas current sports industry development," Fujian Sports Sci. Technol., vol. 3, pp. 3-5, 2013.

[4] H. Hai-yan, Z. Lin, and L. Nan-zhu, "Study on the role of shanghai government in the operation of major sports competition events," China Sport Sci., vol. 27, no. 2, pp.17-25, 2007.

[5] H. Lu, and F. Xiao-chun, " On the connotation of sports events," $J$. Cap. Coll. Phys. Educ., vol. 17, no. 6, pp. 12-13, 2005.

[6] H. Xiao-mao, and Z. Wan-zhou, "Research on the commercialized operation of chinese large physical games with the public welfare," Sci-Tech. Info. Develop. Econ., vol. 17, no. 21, pp.137-138, 2007.

[7] R. Chunxiang, and Z. Jie, "The research on macro-environment of china's sports competition exhibition match industry market," Sports Sci., vol. 25, no. 3, pp. 14-17, 2004.

[8] Z. Liang-jun, C. Xiao-ying, and Z. Xi-kuan, "Status and role of government in sport event exhibition industry: taking shanghai as an example," Sports Sci. Res., vol. 28, no. 4, pp. 48-51, 2007.

[9] Z. Liang-jun, and Z. Xi-uan, "Study on the theory and method of international competitiveness of shanghai sport event industry," $J$. Guangzhou. Phys. Educ. Inst., vol. 26, no. 5, pp. 13-16, 2006.

Received: June 10, 2015

(C) Jiang and Zheng; Licensee Bentham Open.

This is an open access article licensed under the terms of the (https://creativecommons.org/licenses/by/4.0/legalcode), which permits unrestricted, noncommercial use, distribution and reproduction in any medium, provided the work is properly cited. 